\title{
Word-building means in a political leader's speech portrait (implicit pragmalinguistics)
}

\author{
Marina Tyutyunnik ${ }^{1}$ \\ ${ }^{1}$ Don State Technical University, Gagarin Sq., 1, Department "World Languages and Cultures", \\ Rostov-on-Don, 344000, Russia
}

\begin{abstract}
The article is concerned with the implicit pragmalinguistics which studies a person's unconscious choice of verbal means to maximize the impact on the listener. The principles of hidden or implicit pragmalinguistics are put forward. They reveal the dependence of the actualization of hidden grammatical meanings on the speech situation of communication. The present article focuses on the characteristics of blogging as a form of comprehensive political communication. The paper aims at examining the specific features of political online written diaries in open social networks. It is established that the implicit speech influence on mass addressee is carried out by means of speech signals. These verbal signals actualize the plans of emotive and conative-aimed implied speech strategies of the hidden influence of the text sender on its recipient, so the author's speech portrait is drawn up. Grammatical and textual forms of grammatical and textual categories are considered as speech signals. Along with them implicitly influencing derived lexical units formed by various word-building means are presented as verbal signals in the paper. It is formed the concept of speech behavior. According to the key features of a New Zealand politician's speech behavior his personality is revealed. It has been developed in the form of the political leader's speech habits based in the conditions of his national culture.
\end{abstract}

\section{Introduction}

Since the end of the twentieth century, the attention of modern researchers has been increasingly focused on the study of the mutual influence of a person and language as well as on the study of speech communication $[1,2]$. They speculate trying to define how a person manifests himself in the choice of language units, using them as a tool of communication [3]. According to scientific practical surveys a person is proved to be the main figure of verbal activity in the pragmalinguistic research. Within the framework of a given communicative situation it is necessary to take into account both its social and individual characteristics while studying any person's speech behavior. By speech personality we mean a language personality in the paradigm of real communication. In this regard, the relevance of the topic of this study is determined by Russian and foreign linguists' growing interest to the study of the effective verbal influence of a political leader. 
The general aim of the paper is to investigate John Key's speech behavior, who is one of the most prominent political figures in New Zealand, and on the basis of the obtained results to identify some his basic personal peculiarities that are inherent and characteristic of him as a representative of the political social group. The main aim defines the range of goals to be solved within the framework of the presented work:

1) to consider the specific characteristics of such speech genre as written political online diary;

2) to describe the means of actualizing the hidden speech strategies, each of them being presented in the text in the form of its own plans-variants and to identify a small syntactic group as a unit of the pragmalinguistic experiment;

3) to create a fragment of a speech portrait that determines the personality of a New Zealand politician being based on the texts of his online diaries according two speech strategies of hidden influence;

4) to determine and describe the peculiarities of unconscious derived lexical units formed by various word-building means as speech signals according to two hidden speech strategies.

Initially, we take into consideration the reasons motivating us to recognize one person as a leader and deny another the privilege of such recognition. Political leaders have always attracted people's attention with their unforgettable and catchy manner of communication, their unusual bright rhetoric. The peculiarity of political leadership consists of the national leader's ability to produce the effect of political effectiveness on everybody and the society in whole. The personal characteristics of a politician are clearly reflected in his verbal behavior, so the created image must meet the demands of the population.

In this regard, the New Zealand political leader's texts, created by him during the election campaign, are particularly evident. Without pretending to create an exhaustive description of his speech behavior, we turned to his election campaign texts. The New Zealand politician's speech behavior was examined on the text material taking into consideration different word-building means as verbal signals of implicit influence. The campaign texts in Facebook of such speech genre as written diaries were considered as an implementation of the New Zealand variant of the modern English language. It includes the novelty of this study.

In this paper, it is reasonably to evaluate the political text taking into account the specific conditions of its creation and functioning [4]. The authorship of the text and its targeting, the time, place and purpose of its creation are especially important as well as the author's strategy and his tactics.

The books and articles on political communication and political leadership constitute the theoretical basis for this work [5.6]. There should be mentioned the attempts to build psychological portraits of the personality [7].

Recently the problem of anthropocentrism studying language as a means of influence in close connection with a person, his consciousness and thinking has been brought forefront. The shift from the "immanent" to the anthropological linguistic paradigm defines a wide range of problems related to such human sciences as psycholinguistics, sociolinguistics, cultural linguistics, cognitive linguistics, as well as pragmalinguistics [8].

However, in this case, the interest to various aspects of political communication as well as political leader's personal characteristics, was caused by the viewpoint of conscious and unconscious choice of verbal units in typical speech situations [9]. One of the young and complex branches of linguistics, named hidden pragmalinguistics or implicit prafmalinguistics is interested in the automatic choice of hidden speech signals by the text sender. At the same time, it is revealed the dependence of hidden grammatical meanings on 
the verbal situation of communication. In this case we are talking about such hidden grammatical meanings that are found only in a specific speech act, and not in the meaning of the word.

Within the framework of hidden pragmalinguistics, first it was made an attempt by means of pragmalinguistic analysis to describe the personal characteristics of the author of texts based on his speech behaviour [10]. Most of recent analyses apply to the interpretations of verbal practices $[9,11,12]$.

On the hypothesis of this study we assume that the social group of people engaged in politics is characterized by its confident speech behaviour, which is formed due to the national and cultural influence and social status the certain individual possesses.

\section{Materials and methods}

In this article, the study of the New Zealand politician's speech behavior was conducted on the material of his original texts of the speech genre of written diaries. The author of the texts is a political figure, John Key, a former prime minister. He is a fifty year-old man, who was a leader of the New Zealand National party up to 2016. We have examined his written texts, created by him in the time period from 2011 to 2017, when he resigned as the Prime Minister of New Zealand. The total volume of the analyzed text was 800 small syntactic groups as units of analysis, which were diagnosed in the framework of the style of written social network diaries.

The method of research in this work was the method of objective pragmalinguistic experiment. The texts having been collected by means of continuous sampling method, were divided into small syntactic groups (SSG). They are considered as units of account of speech signals.

Application of the received data is finally result in further processing by means of modified content analysis techniques. The detected speech signals are recorded in the tables according to hidden influencing strategies. According to the choice of a particular plan of the strategy also fixed in summary tables the fragment of the author's pragmalinguistic speech portrait is drawn up.

\section{Results}

The results of the study are following. The first step was to establish the basic peculiarity of the author's speech behavior in the texts of written messages in this paper. The speech genre of political online written diaries is characterized by the inevitable author's presence as well as informality, clarity, spontaneity, directness, similarity to everyday dialogue and the retrospective vision of events. In the 21 st century, it is considered relatively recent and one of the most popular ways to convey information to the population. In written political blogs the content is regularly updated. Moreover, the mutual reciprocal communication is expected to be possible which is characterized by the communicative equality of the participants.

The political blogging is characterized by information value, stereotyping, the presence of a multiple addressee, pragmatic attitude, hidden influence on the addressee, and a verbal motivation. Taking into consideration the texts of the election campaign blog, the object of speech influence must necessarily keep the impression of making a decision independently voting for a certain candidate. According to some linguists [13,14,15], political communication performs information surroundings for the politician, aimed at the recipients to form the appropriate perlocutive and post-communicative effect. 
In this regard, we turned to John Key's election online diaries, posted in the open social network "Facebook". It was established that John Key's personal characteristics affecting his speech behavior are concerned with his upbringing, education, psychological peculiarities, his belonging to the male sex, as well as professional and social status.

Speech behavior is referred to the automatic, unconscious choice of speech units from a set of equal language units. This choice is the result of the formed individual verbal experience of the New Zealand politician, which has been developed for all his life in the form of speech habits and preferences in the conditions of his national culture and environment. The actualization of his personal properties in individual speech behavior is registered in three emotive and three conative-oriented implied speech strategies.

So, at the second stage we describe the means of actualization of influencing speech strategies.

Table 1. A fragment of John Key's speech portrait of a written speech genre based on emotiveoriented speech strategies

\begin{tabular}{|c|c|c|c|c|c|c|c|c|c|}
\hline \multirow{3}{*}{ Text } & \multicolumn{3}{|c|}{$\begin{array}{l}\text { Speech strategy } \\
\text { "participation/non- } \\
\text { participation of } \\
\text { communicants in a } \\
\text { speech event }\end{array}$} & \multicolumn{2}{|c|}{$\begin{array}{c}\text { Speech } \\
\text { strategy of } \\
\text { "confident / } \\
\text { unconfident } \\
\text { author's } \\
\text { speech } \\
\text { behavior" }\end{array}$} & \multicolumn{3}{|c|}{$\begin{array}{l}\text { Speech strategy" } \\
\text { evaluation of a } \\
\text { speech event as } \\
\text { real/unreal by the } \\
\text { sender of the text }\end{array}$} & \multirow{3}{*}{ 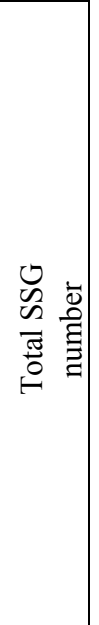 } \\
\hline & \multicolumn{8}{|c|}{ Plan \% } & \\
\hline & 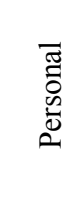 & $\begin{array}{l}\bar{\pi} \\
. \frac{\pi}{0} \\
0\end{array}$ & $\frac{\tilde{0}}{0}$ & 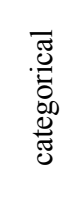 & 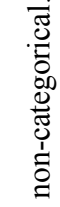 & 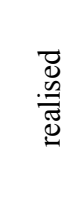 & 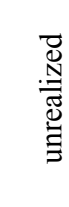 & $\begin{array}{l}\bar{\Xi} \\
\Xi\end{array}$ & \\
\hline Campaign blog & 52.4 & 11.8 & 35.8 & 67 & 33 & 78.8 & 16.4 & 4.8 & 500 \\
\hline
\end{tabular}

Emotive-oriented strategies are aimed at the text sender, while conative-oriented strategies indicate a hidden impact on the recipient of the utterance. The speech strategy of hidden influence is considered as a certain type of speech behaviour of the text sender, which actualizes the particular author's hidden intention in a specific speech situation. The implicit speech influence is actualized by neither the sender nor the recipient of the message in the conditions of realisation of the speech actions in a specific speech act. Speech acts function as a speech signals (markers, actualizers), being realized in the author's speech behaviour. Each strategy is presented in the text in the form of its own plans-variants, and each speech plan corresponds to its own speech markers, implemented in the small syntactic group (SSG). SSG are determined as the "nuclear" components in defining the sentence structure. They are predicate-modal groups that syntactically can be a simple sentence, a dependent clause, a part of a co-ordinating construction or subordinative one, homogeneous parts of the sentence, infinitive, participial and participial phrase or introductory words and constructions. 
Table 2. A fragment of John Key's speech portrait of a written speech genre based on conativeoriented speech strategies.

\begin{tabular}{|c|c|c|c|c|c|c|c|c|c|}
\hline \multirow{3}{*}{ Text } & \multicolumn{3}{|c|}{$\begin{array}{l}\text { Speech strategy } \\
\text { "forming the } \\
\text { recipient's attitude to } \\
\text { the speech event by } \\
\text { evaluating it" }\end{array}$} & \multicolumn{2}{|c|}{$\begin{array}{c}\text { Speech } \\
\text { strategy } \\
\text { "accentuating } \\
\text { the elements } \\
\text { of an } \\
\text { utterance" }\end{array}$} & \multicolumn{3}{|c|}{$\begin{array}{l}\text { Speech strategy } \\
\text { "meeting / not } \\
\text { meeting the } \\
\text { pragmatic } \\
\text { expectations of the } \\
\text { recipient of the } \\
\text { text" }\end{array}$} & \multirow{3}{*}{$\begin{array}{c}\text { Total } \\
\text { SSG } \\
\text { num } \\
\text { ber }\end{array}$} \\
\hline & \multicolumn{8}{|c|}{ Plan \% } & \\
\hline & 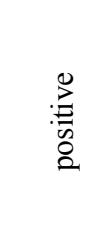 & 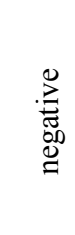 & $\begin{array}{l}\text { 茞 } \\
\underset{\Xi}{\Xi}\end{array}$ & 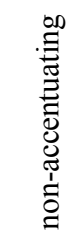 & 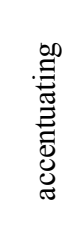 & 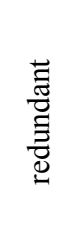 & 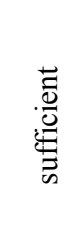 & 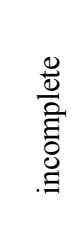 & \\
\hline Campaign blog & 30.2 & 13.8 & 56 & 56.8 & 43.2 & 3.6 & 62.6 & 33.8 & 500 \\
\hline
\end{tabular}

Grammatical and textual forms of grammatical and textual categories, word-building units and lexical intensifiers are considered as speech actualizers in SSG. The frequency of automatic choices of the particular plan indicates the communicator's individual personal characteristics. For example:

Table 3. Actualization the plans of the speech strategy "forming the recipient's attitude to the speech event by evaluating it"

\begin{tabular}{|c|c|c|c|c|}
\hline \multirow{2}{*}{$\begin{array}{c}\text { № } \\
\text { SSG }\end{array}$} & Small syntactic group & \multicolumn{3}{|c|}{ the plan of speech strategy } \\
\cline { 3 - 5 } & & positive & negative & neutral \\
\hline 1 & Moving on to Rotorua | we win the election & + & - & - \\
\hline 2 & There were undoubtedly people & + & - & - \\
\hline 3 & complete with a handful of protesters & + & - & - \\
\hline 4 & $\begin{array}{c}\text { During the mall visit in Christchurch a builder } \\
\text { told me }\end{array}$ & - & - & + \\
\hline 5 & he'd been a life-time Labour voter & - & - & + \\
\hline 6 & Our action plan covers four main areas & - & - & + \\
\hline 7 & Not one person had a negative thing & - & + & - \\
\hline
\end{tabular}

The presence of speech signals is determined by the "+" or "-." signs in the table above. The results of the analysis are reliable enough to be brought in the table and based on both conative and emotive- oriented speech strategies.

Third, within the framework of this article, the most evident positions of John Key's speech behaviour were identified according to two speech strategies.

The "strategy of confident/ unconfident author's behaviour in a speech event" is emotive-oriented and is associated with the text sendert. In the hidden speech strategy 
"confident/ unconfident", the choice of speech signals reveals his confident speech behaviour or determines that his speech behaviour is not confident. This strategy is implemented in two speech plans: categorical (67\%) and non-categorical statements $(33 \%)$. The markers used in the confident strategy or categorical statement may be divided into:

- introductory words of a higher degree of confidence (certainly, indeed, definitely,

moreover, most of all);

- the category of verb tense: present perfect and continuous tense of the active voice;

- infinitive form of the verb "to be";

- infinitive, if the verb it refers to, is in the form of the present or future tense;

- indication of the doer of the action using the passive voice when;

- the category of the future tense of the verb in the passive voice;

- verbs in the imperative mood;

- infinitive sentences;

- the category of the verb of the past tense of the perfect form when denoting the future action;

- modal verbs (must, may, should);

- analytical intensifiers (even, much, many, very, a lot, significantly, a great deal);

- adjectives and adverbs in the superlative degree of comparison (the best, the most useful);

- an indicator of a large number and integrity (the whole, pronouns all, every, each);

- the presence of a superlative seme or an "excessive feature", as well as components indicating an excessive degree of some characteristics (whistlestop, cutting-edge). For example:

1. [Our campaign will be to start], [It's up to you to decide], [National is ready to deliver a fresh approach] [16]. The given speech markers in italics that are grammatical and textual forms of grammatical and textual categories prove the implementation of the categorical statement, therefore his confident speech behaviour. The further implications of the results of the principal goals are explained in the section "Discussion" and the most vivid examples are given there to show the importance and value of the work.

Finally, to analyze the process of composing the speech portrait we apply to the fourth goal to determine various derived lexical units as speech signals in SSG, which also actualize speech strategies.

The individual speech experience can also be judged by the frequency of the author's choice of different or similar derived lexical units. Whereas person's speech experience is acquired in various extralinguistic conditions (some occupation, conditions and place of living) and throughout his speech practice, the frequency of his choice of a particular wordforming model indicates the manifestation of certain features in the personal, professional, and national traits of his character.

Along with the grammatical and textual forms we considered derived lexical units as speech signals of the plan of a categorical statement. They are formed by different means of word-formation such as composition $52 \%$, conversion $24.3 \%$ and suffixation $19 \%$.

Within the framework of the given small syntactic groups, we point out John Key's choice of such derived lexical units as a whistlestop - a series of short visits to different places, undertaken mainly by a politician (formed by word composition), a walk - layer, level (conversion) in the expression walks of life - various social strata of society, characteristic of the American variant of the modern English language, rally (suffixation) a public meeting of a large group of co-thinkers. This fact also indicates the professional and national preferences of the New Zealand politician in his speech behaviour. Although 
the politician has equal opportunities to choose another derived unit from the set of available in the language arsenal (such as commuting, layover, stopover, business-trip) that reflect different types of trips in their semantics, he prefers the whistlestop speech signal. Whereas this speech marker serves as an indicator of a large ammount for actualizing a categorical statement along with other language units, some of them are mainly used in political communication. For example:

2. [The pupils here are being equipped with the use of cutting-edge information technology] [16]. Along with the synonymous unit bleeding-edge John Key makes an unconscious automatic choice towards the complex adjective cutting-edge, indicating an excessive degree of the feature. As this marker (speech signal) contains a seme of superlative characteristic and serves to actualize the plan of categorical approval, focusing the voter's attention on the positive achieved results. This example also illustrates the speech signals of the categorical statement plan from the written texts of the examined network diaries.

Let us appeal to the analysis of the speech behaviour of the New Zealand leader according to the conative-oriented strategy of hidden speech influence "formation of the recipient of the text's attitude to the speech event through evaluation" (further as "attitude formation"). The conative strategy is focused on the recipient of the text, who is maid a certain impact. The author's evaluative attitude to the subject or phenomenon of reality in the speech situation is implemented in this speech strategy. Such an evaluative attitude can be positive, negative or neutral. Therefore, the strategy is presented in the text in the form of three plans: positive $(30.2 \%)$, negative $(13.8 \%)$ and neutral $(56 \%)$. The words and statements that cause a positive associative attitude are represented as speech signals of the plan of a positive attitude. Markers of positive evaluation are words with positive semantics (to win) containing:

- a socially determined component that determines the behaviour of members of this social group (to campaign);

- word-building/derivational component, such as suffix -ing, -ful (amazing, exciting, handful);

- component of importance, accuracy, similarity (valuable);

- component of magnitude, measure (additional \$ 500 million);

- the meaning of superiority (best, cutting-edge);

-also modal-evaluative particles and introductory words (undoubtedly);

- evaluative words of a recommendatory nature, expressing advice or modal verbs (to tend, to recommend, should). For example:

3. [Moving on to Rotorua | we win the election] [16].

4. [There were undoubtedly people | who vote Labour there | complete with a handful of protesters] [16].

The recipient of the text forms an idea of the speaker's attitude to what he is talking about, according to the choice of evaluative markers the sender of the text made. Words with positive semantics, modal introductory words (to win, undoubtedly) mark the author's positive assessment. The noun handful is formed by means of word-building means and possesses the shade of positive evaluation. Being determined by the author's choice, it actualizes the plan of positive evaluation. Markers of negative attitude appear to be evaluative vocabulary with negative semantics, negation, introductory words of negative evaluation. The plan of the neutral attitude of speech influence is implemented in the absence of speech signals of positive and negative evaluation. 


\section{Discussion}

Applying to the results of the paper we place in the forefront the specific characteristics of speech genre as political online written diaries. In the process of racing for power, politicians make verbal influence on the listener. In this connection, the analysis of the political discourse, aimed at identifying the unconscious speech behavior of communicants, seems to be relevant in the anthropocentric paradigm of a person as a subject of speech activity.

It should be recognized that the Internet with its feedback communication in blogs, social networks, YouTube, etc., contrasting it to the genre of public speaking, played a significant role. Blogs are a kind of online diaries with regularly updated content, they provide the opportunities mutual communication to each Internet user. They proved to be a powerful means of communication, creating various opinions on the discussing issues. One of the methods of election communication with potential voters is the political written blogging in order to make them agree with the point of view of the author and choose a given political candidate.

At the same time, politicians in their online diaries try to be natural clear in their statements, bringing their pre-election speeches closer to the everyday dialogue. It makes the impression of special sincerity and confidence, allows to establish contact with a potential voter, giving the sender of the message more opportunities for self-expression than in official environment [17].

The politically orientated texts posted in online diaries are characterized not only by informativity, interactivity, stereotyping, ease of use, informality, and equal communicative rights of Internet users, but also by a pragmatic attitude, open and hidden manipulative influence $[18,19]$. It can be clearly viewed that the main purpose of political communication is aimed to encourage and motivate the addressee to take political action. It should be mentioned that speech motivation becomes the leading strategy in this type of speech activity. Speech motivation is realized in the concept of a speech strategy of hidden influence and implies different speech behaviour of the text sender in a certain speech situation.

In accordance with the hidden influencing strategy of "confident / unconfident speech behaviour of the author" in the speech event of the blog genre, the New Zealand politician's categorical statements constitute $67 \%$. The choice of markers for the categorical plan characterizes him as an initiative, decisive, independent and self-confident person. He is a political leader with an active lifestyle and social position, focused on success. For example:

5. [The best part of the campaign has been meeting New Zealanders from all walks of life] [16].

The speaker estimates his statements as being true with a greater degree of certitude, expressing an emotional attitude of assurance. Automatically choosing the superlative markers best, the form of the present perfect continuous tense has been meeting, and the definite pronoun all as an indicator of a large number and integrity, the Prime Minister of New Zealand aims himself and the prospective voter at the success. Confident speech behavior is inherent with persistent, energetic and determined people. He inspires confidence in the interlocutor in his views, invites New Zealanders to become co-thinkers in achieving common goals. Taking into account all these characteristics we are assured in New Zealand leader's determination and firmness in his statements. His choice of markers of the plan of categorical utterance proves the idea that his personality is characterized by categorical views, independence, a high level of self-esteem, confidence. 
According to the conative hidden speech influencing strategy "forming an attitude to a speech event" the preference in John Key's written texts is given to the plan of forming a neutral attitude to a speech event. This plan represents $56 \%$. For example:

6. [During the mall visit in Christchurch a builder told me] [he'd been a life-time Labour voter] [16].

7. [Our action plan covers four main areas] [16].

As there are no speech signals of positive or negative assessment of a speech event in these examples, the neutral evaluation is implemented here.

The dominance of the plan of neutral evaluation creates the effect of a real and adequate image of the objective reality. With the allowance for the politician he takes a position of neutrality in social networks, stepping aside in relation to the presented material, he gives an opportunity to the voter to draw his own conclusions. The author's choice of neutral speech signals in the text preserves the impression of independent decision-making by the object of speech influence. This fact proves the features of informality of the blogging making up the communicative equal rights of Internet users.

A fairly high indicator of the plan of positive assessment of the presented content $(30.2 \%)$ indicates John Key's inherent optimism and cheerfulness. The choice of positive markers of agreement "yes" and approval "care" actualizes a positive assessment, the ability to find something in common with the interlocutor, as well as get caught up into the details of all the issues. For example:

8. [Yes, because quality education is something | I care passionately about] [16].

It is a case in point of being positive to the objective reality and to people, his audience forms a positive attitude to the reported information. A low indicator of the plan of negative attitude $(13,9 \%)$ denies melancholy or anxiety as his traits of character.

In the Internet blogging, the blogger John Key is distinguished as a bright, but not too high emotionally political leader. The most serious advantage he possesses is persuasiveness of speech and the ability to feel the audience. It is so evident through the actualizing of the plan of positive and neutral assessment, as well as the plan of categorical statement. He is eager to appeal to the mass audience in a natural manner close to the everyday dialogue. This construction of speech gives the impression of sincerity and ease, with the allowance for implementation of his implicit traits of character.

To draw a precise fragment of a speech portrait of a New Zealand politician, we turned to the word-formation features of his online diaries. As to various means of word formation, affixation takes the predominant position. It is represented by $52.2 \%$ (among all derived words in two given speech strategies). These are words a New Zealander, an offender, an endorsement, to overcome, outside. For instance:

9. [It was an exciting day for me in South Auckland yesterday] [when I] [and National got endorsement from two sporting greats] [16]. Positive evaluation is implemented by selecting the lexical units exciting, endorsement, great, which contain a positive motivation. The suffix "- ment" is added to the verbal base and is used to form nouns denoting the state, quality, or result of an action.

It should be noted that our attention was attracted by John Key's choice of the noun great (formed by means of conversion from the adjectival stem great) when he described two sports players. As it has been mentioned, along with such existing English synonyms as star, celebrity (also denoting famous people), he chooses this particular verbal signal being based on his own speech experience and habits. The speech marker "great" along with its lexical and grammatical meaning, also actualizes additional nuances of signification. We also take them into account while building an author's speech portrait. By this notion, we mean the positive content of the hidden impact that was implemented by New Zealand leader at the moment of speaking instantly in this particular speech action. In contrast to the 
connotative meaning, which is part of the lexical meaning of the word in the language system, the nuances of signification or hidden intentions of the author of the text appear only in real verbal communication. And they actualize in the speech signals of hidden influencing strategies. Concerning SSG from the point of view of modality, we have investigated such derived speech signals only in the hidden speech strategies "formation of attitude to the speech event" and "confident/unconfident speech behavior of the author" in the speech event.

From the results it may be stated that according to investigated derived speech markers John Key can be described as a determined, ambitious politician. It is proved by the choice of the words formed by means of composition (24.3\%). A lot of them are positively and neutrally colored lexical markers with the semantic component of an excessive degree, indicating concreteness and uniqueness, such as: ultra-fast, broadband, computer-savvy (informal), a talkback (Australian variant). For example:

10. [Clover Park is a computer-savvy school] [that makes the most of ultra-fast broadband] [16]. The hidden strategy of "confident / unconfident behavior" is actualized through the speaker's subjective emotional attitude to the objective reality. In this case the actualizers in bold with a seme of superiority express his confidence towards the truth statement.

Some of the lexical units are neutral toponyms, such as Auckland, Christchurch, Tauranga, Rotorua, Queenstown. We refer them to the neutral speech markers, they are also built by means of composition. The choice of emotionally calm derived speech signals reflects New Zealand politician's speech characteristics as being calm, peaceful and unflappable.

The conversion rate is $19 \%$, including adjectives, nouns, and verbs: to campaign, a walkabout (Australian, British variants, informal), to face, to focus, cutting-edge. It should be noted that John Key chooses mostly the verbs formed by means of conversion as the derived markers. Consequently, conversion proves to be one of the most productive means of word-formation of New Zealand variant of the modern English language. Verbs built by means of conversion often include an entire phrase in their meaning, conveying the "concentrated" signification in a single form. It saves the lexical means in case of limited language resources. Moreover, the verb as a part of speech, possessing predicativeness and mood, is included in each SSG. For example:

11. [Yesterday I spent time campaigning in Tauranga] [and Rotorua] [16].

12. [I've continued to be focused on the issues] [that matter to New Zealanders] [16]. Given examples reveal the verbs in the role of derived verbal signals, implemented in the given speech action.

Abbreviated words accounted for only $4.5 \%$, despite the fact that this means of word formation is actively used in informal correspondence and Internet chats, for example: $B B Q$ (barbecue), Newstalk $Z B$ - the name of the radio program.

13. [We flew in a chartered plane to Napier for a breakfast BBQ] [16].

14. [From there I did an hour of talkback with Leighton Smith on Newstalk ZB [16].

\section{Conclusion}

These above mentioned findings make it possible to conclude that politicians' speech is always aimed at influencing the mass consciousness. As a result politicians as a social group are of a great interest to researchers in various branches of linguistics. Open social networks like "Facebook" are able to set a certain information and communication environment around the New Zealand politician, John Key. The New Zealander's 
communications behavior is marked by the pragmatic goals and hidden audience impact. The analyzed survey convincingly shows that the New Zealand politician's personality is manifested in his speech behavior and reflects his individual speech experience in the conditions of his national culture to which the individual belongs. The whole variety of all his characteristics can be reduced to a few ones that are deduced from this pragmalinguistic experiment.

From the viewpoint of implicit pragmalinguistics, derived lexical units formed by various means of word formation along with markers of grammatical and textual categories also appear as actualizers of hidden influencing strategies in the New Zealand politician's online diaries.

A fragment of the New Zealand politician's John Key speech portrait based on his written texts reveals him as a full-fledged multidimensional political leader. According to the speech signals of all the analyzed plans of hidden speech strategies we have drawn up a fragment of his speech portrait. This method is rather efficient as we can reveal and describe some individual properties of the text sender. Thus, the results of the survey lead to a conclusion that John Key is a realist in politics. He manages to keep calm, flexible and not rather emotional. But at the same time he is an ambitious and determined leader with high self-esteem. This politician knows how to win the people over.

\section{References}

1. S.V. Pervukhina, V.I. Demchenko, E3S Web of Conferences, 210, 1-10 (2020) doi.org/10.1051/e3sconf/202021018033

2. M. Round, P. Isherwood, Trends in Anaesthesia and Critical Care, 36, 23-29 (2020) doi: 10.1016/j.tacc.2020.08.006

3. A. Beard, Paediatrics and Child Health, 28, 126-131 (2018) doi:10.1016/j.paed.2017.12.004

4. K. Ikeda, Language \& Communication, 33, 351-365 (2013) doi:10.1016/j.langcom.2013.04.003

5. O. Papakyriakopoulos, J. C. Medina Serrano, S. Hegelich, Online Social Networks and Media, 15, 1034-1042 (2020) doi:10.1016/j.osnem.2019.100058

6. A.P. Chudinov, Political linguistics, 2 (40), 53-59 (2012)

7. I. Zyubina, A. Dzyubenko, G. Matveeva, K. Ostrovskaya, A. Ratokhina, 3rd International Multidisciplinary Scientific Conference on Social Sciences and Arts SGEM 2016, 1, 245-250 (2016) doi: 10.5593/SGEMSOCIAL2016/B11/S01.032

8. S.V. Pervukhina, G.G. Matveeva, Proceedings of the X International Conference "Word, Utterance, Text: Cognitive, Pragmatic and Cultural Aspects", 124, 1064-1074 (2020) doi: 10.15405/epsbs.2020.08.124

9. G. Matveeva, G. Myasischev, O. Gaibaryan, E. Shirina, E3S Web of Conferences, 210, (2020) doi.org/10.1051/e3sconf/202021016011

10. G. Matveeva, I. Zyubina, Language and Speech in Synchrony and Diachrony, 284291 (2017)

11. I. Zyubina, A. Dzyubenko, G. Matveeva, A. Ratokhina, G. Ostrikova, $4^{\text {th }}$ international multidisciplinary scientific conference on social sciences and arts SGEM 2017, 17(2), 1089-1094 (2017) doi: 10.5593/sgemsocial2017/32/S14.141

12. M.A. Fokina, The phenomenon of precedent in Russian political discourse: on the politicians' blogs, Abstract of Ph. D. thesis, 24 (2017) 
13. C. Conrad, K. Ulrich Zumbach, Journal of Empirical Finance, 39, 209-214 (2016) doi:10.1016/j.jempfin.2016.01.018

14. A. Haselow, Language Sciences, 82, (2020) doi:10.1016/j.langsci.2020.101334

15. D. Z. Kadar, Fengguang Liu, Juliane House, Discourse, Context \& Media, 35, (2020) doi:10.1016/j.dcm.2020.100384

16. J. Pal, A. Donawela, Current Opinion in Behavioral Sciences, 18, 97-102 (2017) doi:10.1016/j.cobeha.2017.09.009

17. J. Mathieu Tsoumou, Journal of Pragmatics, 167, 80-97 (2020) doi: 10.1016/j.pragma.2020.06.004

18. E.A. Tikhomirova, Yurislinguistica, 6, 102-115 (2017) 